\title{
IMPLANTAÇÃO DO 5S E 5W2H EM UM PACKING HOUSE DE MANGA: ESTUDO EM EMPRESA ALIMENTÍCIA DE PEQUENO PORTE
}

\section{ARTIGO ORIGINAL}

SOUSA, Gilismar Cesar Ramos ${ }^{1}$

BATISTA, Karina Vieira Dos Santos ${ }^{2}$

REVOLTI, Luís ${ }^{3}$

RIBEIRO, Rafael Fernando ${ }^{4}$

SOUSA, Gilismar Cesar Ramos. Et al. Implantação do 5S e 5W2H em um Packing House de manga: Estudo em empresa alimentícia de pequeno porte. Revista Científica Multidisciplinar Núcleo do Conhecimento. Ano 05, Ed. 06, Vol. 05, pp. 1939. Junho de 2020. ISSN: 2448-0959, Link de acesso: https://www.nucleodoconhecimento.com.br/engenharia-deproducao/packing-house

\section{RESUMO}

O trabalho teve como objetivo analisar a implantação das ferramentas metodológicas 5 s e $5 \mathrm{w} 2 \mathrm{~h}$ em um Packing House de manga, empresa de pequeno porte do ramo alimentício no interior do estado de São Paulo, além de demonstrar as contribuições e melhorias realizadas com a implantação das ferramentas, tanto para empresa quanto para seus colaboradores. Foram utilizadas informações cedidas pela empresa e realizada a comparação de resultados de antes e depois das implantações

\footnotetext{
${ }^{1}$ Graduando Engenharia de Produção.

2 Graduando Engenharia de Produção.

${ }^{3}$ Graduando Engenharia de Produção.

${ }^{4}$ Pós Graduado em Engenharia de Estruturas.
} 
realizadas, o que visou a diminuição de desperdícios, a melhoria na higiene, assim como a ordenação na linha de produção, a limpeza e a autodisciplina de todos os envolvidos. Foi considerada a implantação das ferramentas 5 s e $5 \mathrm{w} 2 \mathrm{~h}$, sem nenhuma experiência anterior, sendo este o primeiro contato da empresa com as ferramentas de qualidade citadas. Foram utilizadas pesquisas de livros, artigos científicos e normas de segurança. Com a conclusão da pesquisa, foram notadas melhorias nos 5 sensos implantados na empresa e da metodologia $5 \mathrm{w} 2 \mathrm{~h}$, além de uma melhoria na relação entre colaboradores e da alta cúpula da empresa. Caso ocorram problemas na execução ou na implantação das ferramentas de qualidade, a probabilidade dos desperdícios e das perdas durante o passar do tempo será de grandes proporções. Sendo assim, foram aplicadas as metodologias $5 \mathrm{~s}$ e $5 \mathrm{w} 2 \mathrm{~h}$, especificamente para 0 ramo alimentício, com a finalidade de minimizar ou até mesmo sanar os problemas existentes na empresa.

Palavras-chave: Gestão da qualidade, programa $5 \mathrm{~S}$, método $5 \mathrm{~W} 2 \mathrm{H}$, pedúnculo, manga.

\section{INTRODUÇÃO}

Com o avanço das tecnologias e o aumento exponencial de habitantes no planeta, o ser humano tem buscado novas formas de manter os recursos vitais para sua sobrevivência, seja na forma de preservação, racionamento ou reaproveitamento. $\mathrm{Na}$ década de 1950, as empresas japonesas encontraram ferramentas que amenizavam os prejuízos da forte crise que afetava o país na época, que acabava de se recuperar das cicatrizes deixadas na economia nacional após a Segunda Guerra Mundial. As ferramentas aplicadas outrora em terras nipônicas foram trazidas para o Brasil na década de 1990, com intuito de melhoria na linha de processos para fabricação de produtos e, desde então, vem sendo aplicadas em empresas de grande, médio e pequeno porte (LOBO, 2002).

No momento atual as empresas que ainda não aderiram aos programas de melhoria estão ficando obsoletas e perdendo força no mercado, ocasionando até mesmo o seus 
fechamentos, e nos piores casos, decretando falência. Outro ponto que foi detectado é que diante de metodologias arcaicas, estas usadas na maioria das empresas de pequeno porte, por motivo de resistência em implantar novos sistemas e devido à desconfiança de sucesso na inserção dos novos planos, estas empresas tendem a ter um declínio em suas vendas. Com isso, as empresa estão estendendo e focando suas atenções no setor da gestão da qualidade, em instituições de todos os portes; certas ferramentas implantadas na gestão de qualidade vêm sendo a grande saída, diminuindo gastos, aumentando eficiência e possibilitando uma melhor relação entre corporação e funcionário. Além da implantação dos programas de qualidade já elencados vale ressaltar outros benefícios constatados como: padronização no serviço, aumento na qualidade do produto, melhor desempenho na produção, tomadas de decisões mais assertivas, redução de custos por desperdício de tempo e de matéria-prima, organização e melhor aproveitamento do espaço físico entre outros que iremos citar ao decorrer da pesquisa.

As ferramentas aqui aplicadas levam o nome de $5 \mathrm{~S}$ ou cinco sensos, como é chamada no Brasil, e 5W2H, ferramenta poderosa na elaboração de planos de ação. Este trabalho tem como intenção destacar os principais pontos positivos na adesão das metodologias $5 \mathrm{~S}$ e $5 \mathrm{~W} 2 \mathrm{H}$, bem como suas características e necessidades, focando em um resultado final que realmente seja funcional para as empresas. Diante disso, foi analisada implantação dos tais programas, em uma empresa de pequeno porte do setor alimentício no interior do estado de São Paulo, mais precisamente em uma Packing House de manga.

Os resultados obtidos podem ser aplicados às diferentes empresas, de diferentes setores, já que as metodologias são abrangentes e suprem as necessidades de praticamente todos os ramos industriais no Brasil.

Nesta implantação foi levada em consideração a situação atual da empresa, da qual não havia nenhuma experiência anterior com qualquer tipo de ferramenta da qualidade. 
As falhas mais frequentes constatadas foram: controle inadequado de temperatura na estocagem dos frutos falta de pulverização de agrotóxico no sistema de estocagem, resíduos no estoque, insetos no ambiente de armazenamento, deformações da fruta e entre outras falhas que comentaremos mais à frente.

Podendo ser aplicada as seguintes soluções para as falhas citadas acima: regulagem e/ou dimensionamento do controle de temperatura eliminando as deformações das frutas e acionando a pulverização regulada no sistema de agrotóxicos eliminando os insetos no ambiente, utilização de roupas adequadas eliminando possíveis resíduos no estoque.

Foi obtido sucesso dos resultados analisados implantando os seguintes tópicos: dimensionamento e implantação do controle de temperatura, de pulverização e mantendo o local limpo e organizado.

A pesquisa é de grande valia e pode ser implantado nos seguintes setores como, por exemplo: agriculturas, indústrias, usinas em geral, siderúrgicas, metalúrgicas, mineração entre outros.

Esse trabalho visa contribuir com a análise da Gestão da Qualidade e Logística como um todo e será desenvolvido com base em bibliografias tais como (BOONE; KURTZ, 1998; CANDELORO, 2008; NAKAGAWA, 2014; RIBEIRO, 1994; SILVA, 2013; VIEIRA, 2002) entre outros que falam sobre os assuntos mencionados ao longo da pesquisa. Com embasamento nas normas competentes do setor de estoque/alimentos e do setor de $5 \mathrm{~S}$ e $5 \mathrm{~W} 2 \mathrm{H}$.

Será realizado um banco de dados prévio para comparar os resultados obtidos no desenvolvimento deste trabalho.

\section{OBJETIVO GERAL}

Este trabalho teve por objetivo a implantação do programa $5 \mathrm{~S}, 5 \mathrm{~W} 2 \mathrm{H}$ numa empresa de pequeno porte, situada no interior de São Paulo, uma empresa familiar de pequeno 
porte em atividade desde 1980 e que conta com 18 colaboradores no seu quadro de funcionários. Produzindo mangas de alta qualidade, atendendo principalmente o mercado do Ceasa. Visando melhorar ainda mais seu ambiente de trabalho e a necessidade de organizar determinados setores a direção mostrou grande interesse na implantação do programa de qualidade $5 \mathrm{~S}$ e $5 \mathrm{~W} 2 \mathrm{H}$.

O trabalho visa analisar, instalar, qualificar, aplicar e comparar resultados, através das ferramentas da qualidade, além de desenvolver e incorporar os resultados obtidos. Compreender as aplicações conciliando as vantagens e desvantagens da situação, levando em consideração os problemas típicos enfrentados no momento da produção.

\subsection{OBJETIVOS ESPECÍFICOS}

O trabalho tem como objetivos específicos:

- Analisar o desempenho da produção antes da implantação das ferramentas da qualidade com auxílio de materiais de apoio e pesquisas em gestão da qualidade;

- Comparar os resultados após aplicação das ferramentas da qualidade, levando em consideração todos os dados obtidos, relatando pontos positivos e negativos após sua aplicação;

- Aplicar as metodologias em todos os níveis da empresa, levando em consideração o aspecto de qualidade total, para reduzir desperdícios, tempo ocioso, aumentar os lucros e os atributos positivos do produto final.

\section{METODOLOGIA}

\subsection{FERRAMENTA 5S}

5s como metodologia da qualidade tem por objetivo a reorganização e limpeza do ambiente de trabalho, em conjunto com a autodisciplina dos colaboradores, podendo proporcionar um ambiente saudável e produtivo. A metodologia tem como foco a 
eliminação dos desperdícios no local de trabalho e o aperfeiçoamento nas mudanças da organização (LAES; HAES, 2006).

Termologia senso deve ser utilizada para manter o $S$ em cada palavra japonesa, traduzida para o português: Seiri, Seiton, Seisou, Seiketsu e Shitsuke. (RIBEIRO, 1994).

Seiri: Senso para utilização e descarte, Seiton: Senso para arrumação, Seiso: Senso para Limpeza, Seiketsu: Senso para autodisciplina.

Seiri Senso de utilização Segundo Abrantes (2007), o propósito deste senso é definir de maneira clara os objetivos, pode-se acreditar que a implantação deste senso seja eficiente e simplificada. Agrega a correta utilização de equipamentos, que tende ao aumento de sua vida útil, além de incentivar a economia de materiais. De maneira geral, o senso de utilização implica na guerra contra desperdícios (SILVA, 1994).

Seiton Senso de arrumação: Conforme Silva (1994), este senso consiste na definição de ambientes para estocar equipamentos e utensílios de modo a facilitar o uso, de maneira popular pode-se traduzir como ponto importante que diz respeito à organização, onde os envolvidos se comprometem em disponibilizar um tempo de sua jornada para planejar sua rotina, priorizando otimização de tempo.

Seiso Senso de limpeza: Este envolve manobras consideradas oportunidades para evitar a sujeira no ambiente, realizando inspeções, as quais possuem a capacidade de descobrir as fontes de sujeira e possíveis pontos de desperdícios. O Seiso contribui para se prevenir contra acidentes, por isso envolve a segurança do trabalho, os bons costumes ambientais, e melhorias na qualidade do trabalho (ABRANTES, 2007). Quando se elimina as impurezas do ambiente tende-se a uma impressão de melhoria e em consequência se vincula os colaboradores e clientes o sentimento de prazer no ambiente da empresa (VANTI, 1999).

Seiketsu Senso de padronização. A padronização cria condições que favorecem o ambiente, através da utilização em conjunto aos outros sensos, de acordo com 
orientações do Seiketsu praticadas. Para Carvalho (2011), as normas do programa vão se aprimorando e transformando os ambientes de trabalho mais agradáveis. Também envolve a mudança de comportamento dos colaboradores, desfazendo vícios obsoletos.

Shitsuke Senso de autodisciplina: Senso da autodisciplina envolve o habito de cumprir normas e procedimentos, este ato deve ser seguido diariamente e controlado por todos. Shitsuke está ligado diretamente com o aprimoramento de padrões, onde a priorização da metodologia deve ser constante. Para o controle deste senso, Lobo (2012), indica a utilização de planilhas de verificação e avaliação, explorando também o uso de auditorias.

\subsection{FERRAMENTA 5W2H}

Segundo Silva, et al (2013, p. 3), "A ferramenta $5 \mathrm{~W} 2 \mathrm{H}$ foi criada por profissionais da indústria automobilística do Japão como uma ferramenta auxiliar na utilização do PDCA, principalmente na fase de planejamento."

Polacinski (2012) afere que esta ferramenta deve refletir em um plano de ação que envolva as atividades pré-estabelecidas e precisam se desenvolver com uma maior abrangência e realizar um mapeamento, priorizando o foco da ferramenta $5 \mathrm{~W} 2 \mathrm{H}$, que é responder, analisar as questões e organiza-las.

Nakagawa (2014) afirma que a ferramenta é útil na sua utilização tanto sozinha para tomar decisões na empresa quanto vinculada a outras ferramentas da Qualidade.

Segundo Candeloro (2008) 5W2H pode ser considerado um checklist utilizado para garantir que a operação seja conduzida sem duvidas pela parte dos gestores e colaboradores. $5 \mathrm{~W}$ significa What (o que): Who (quem): Where (onde): When (quando) e Why (porque). Os $2 \mathrm{H}$ : How (como) e How Much (quanto custa). Ao definir uma ação que deve ser tomada, desenvolvendo uma tabela no formato $5 \mathrm{~W} 2 \mathrm{H}$, que se transforma em um quadro onde estão dispostas as perguntas e o que se espera de 
cada uma delas. O Quadro 1 mostra os métodos da ferramenta da Gestão da Qualidade 5W2H.

Quadro 1: Método da ferramenta da Gestão da Qualidade 5W2H

Método da ferramenta da Gestão da Qualidade 5W2H

\begin{tabular}{|l|l|l|l|}
\hline 5W & What? & O que? & Que ação será executada? \\
\hline Who? & Quem? & $\begin{array}{l}\text { Quem irá executar/participar da } \\
\text { ação? }\end{array}$ \\
\hline Where? & Onde? & Onde será executada a ação? \\
\hline When? & Quando? & Quando a ação será executada? \\
\hline Why? & Por quê? & Por que a ação será executada? \\
\hline How? & Como? & Como será executada a ação? \\
\hline How & Quanto & Quanto custa para executar a \\
much? & custa? & ação? \\
\hline
\end{tabular}

Fonte: Meira (2003).

Candeloro (2008) identificou os significados de cada pergunta da ferramenta, facilitando o reconhecimento de cada item, assim como é exemplificado no Quadro 2.

Quadro 2: Tabelas das perguntas da ferramenta da qualidade $5 \mathrm{~W} 2 \mathrm{H}$

\begin{tabular}{|l|l|}
\hline Pergunta & Palavra-chave \\
\hline O que? & Etapas \\
\hline Por quê? & Justificativa \\
\hline Quando? & Tempo \\
\hline Onde? & Local \\
\hline Quem? & Responsabilidade \\
\hline Como? & Método \\
\hline Quanto custa? & Custo \\
\hline
\end{tabular}

Fonte: adaptado de Candeloro (2008).

Disponível em: https://www.nucleodoconhecimento.com.br/engenharia-de-producao/packinghouse 
O fundamento, segundo Vieira (2002, p. 67), "O objetivo principal é tornar uma situação ou dificuldade complexa em um cenário mais nítido e facilitador".

Segundo Roesch (2005), a pesquisa qualitativa é elaborada com foco em uma análise bibliográfica mais adequada para a situação, propondo planos que enfatizem a solução de problemas já diagnosticados.

Para uma pesquisa exploratória deve-se utilizar métodos versáteis, fazendo um arranjo de fontes secundárias, arranjos experimentais, estudo de casos e análises informais.

Para Malhotra (2001) o foco principal de uma pesquisa explanatória é fornecer a possibilidade de compreensão do problema que o pesquisador enfrenta.

Boone e Kurtz (1998) descrevem que uma pesquisa de caráter exploratório é de maneira enxuta utilizada para descobrir a raiz de um problema.

Foram aplicadas as fases do $5 \mathrm{~W} 2 \mathrm{H}$, onde enfatizou que a solução do problema na pesquisa avaliatória, foi à introdução da ferramenta $5 \mathrm{~W} 2 \mathrm{H}$ como auxílio na criação transporte de mangas de um setor, fundamentada através do estudo de caso realizado no setor, sendo assim a reforçar a importância destes processos em um setor. Esta ferramenta pode ser utilizada em empresas de qualquer segmento, podendo até mesmo ser utilizada como base de estudo para facilitar, aumentar e atender necessidades de cada setor desejado, com foco nos setores industriais, que são regidas por uma regulamentação da Gestão da Qualidade mais complexa que as demais.

\subsection{APLICAÇÃO DO 5W2H PARA A ELABORAÇÃO DO SETOR DE TRANSPORTE RURAL}

O princípio da Gestão da Qualidade é complexo, organizar pode-se tornar uma tarefa difícil. Sendo assim, aconselha-se a aplicação da ferramenta da Gestão da Qualidade 5W2H para facilitar na aplicação no setor de estoque, de modo a reduzir a dificuldade 
de organizar o transporte de cargas, de maneira que os gestores e colaboradores da empresa tenham total entendimento, preparo e treinamento da ferramenta da qualidade, para que não cause nenhum conflito de compreensão da ação da ferramenta.

A aplicação da ferramenta da Gestão da Qualidade 5W2H auxilia na criação de um setor de transporte rural, devendo-se adaptar e harmonizar às sete perguntas da ferramenta, sendo explicada no Quadro 3.

Quadro 3: Perguntas referentes à ferramenta da Gestão da Qualidade 5W2H no setor de transporte rural

Perguntas referentes à ferramenta da Gestão da Qualidade 5W2H no setor de transporte rural

\begin{tabular}{|c|c|c|c|}
\hline \multirow[t]{5}{*}{$5 W$} & What? & O que? & O que é o $5 \mathrm{~W} 2 \mathrm{H}$ no setor de transporte rural? \\
\hline & Who? & Quem? & $\begin{array}{l}\text { Quem criará o } 5 \mathrm{~W} 2 \mathrm{H} \text { no transporte rural? Quais } \\
\text { serão os setores? Quem serão as pessoas } \\
\text { responsáveis? }\end{array}$ \\
\hline & Where? & Onde? & Onde o 5W2H será criado? Em qual empresa? \\
\hline & When? & Quando? & $\begin{array}{l}\text { Quando o } 5 \mathrm{~W} 2 \mathrm{H} \text { será criado? Quais os prazos } \\
\text { estabelecidos para o cumprimento da } \\
\text { ferramenta? }\end{array}$ \\
\hline & Why? & Por quê? & $\begin{array}{l}\text { Por que criar o } 5 \mathrm{~W} 2 \mathrm{H} \text { ? Qual a sua importância? } \\
\text { Qual o seu objetivo? Justificativa da criação } \\
5 \mathrm{~W} 2 \mathrm{H} \text { no setor alimentício. }\end{array}$ \\
\hline \multirow[t]{2}{*}{$2 \mathrm{H}$} & How? & Como? & $\begin{array}{l}\text { Como o } 5 \mathrm{~W} 2 \mathrm{H} \text { será criado? Qual a sua } \\
\text { metodologia? }\end{array}$ \\
\hline & $\begin{array}{l}\text { How } \\
\text { much? }\end{array}$ & $\begin{array}{l}\text { Quanto } \\
\text { custa? }\end{array}$ & $\begin{array}{l}\text { Quanto custa para a empresa aplicar essa } \\
\text { ferramenta? Quais serão os gastos? }\end{array}$ \\
\hline
\end{tabular}

Fonte: Dos autores (2015)

Disponível em: https://www.nucleodoconhecimento.com.br/engenharia-de-producao/packinghouse 
O Quadro 3 mostra as sete perguntas referentes à ferramenta da Gestão da Qualidade $5 \mathrm{~W} 2 \mathrm{H}$, que após serem respondidas, facilita a solução do problema do transporte rural, seus objetivos, métodos aplicados e, com estas perguntas já respondidas, é possível planejar os esforços e ações da empresa, de acordo com as rotinas e atendendo as necessidades. No quadro abaixo estão expostos os objetivos básicos de cada pergunta contextualizados à aplicação da ferramenta da Gestão da Qualidade.

Quadro 4: Elaboração do quadro de perguntas e respostas da ferramenta 5W2H

Objetivos das perguntas da ferramenta $5 \mathrm{~W} 2 \mathrm{H}$ para o setor alimentício

\begin{tabular}{|c|c|c|}
\hline What? & O que? & $\begin{array}{l}\text { Esta pergunta visa apresentar à aplicação aos envolvidos no } \\
\text { processo, de modo a realizar uma apresentação básica do } \\
\text { mesmo e como ele funciona. }\end{array}$ \\
\hline Who? & Quem? & $\begin{array}{l}\text { A empresa deverá estabelecer quais setores participarão do } \\
\text { processo de elaboração do } 5 \mathrm{~W} 2 \mathrm{H} \text { e quais serão as pessoas } \\
\text { responsáveis pela elaboração do mesmo, bem como o seu } \\
\text { público alvo. }\end{array}$ \\
\hline Where? & Onde? & $\begin{array}{l}\text { Esta pergunta visa basicamente responder em qual setor será } \\
\text { aplicado e, em caso de parcerias, quais outros } \\
\text { setores/empresas estão envolvidos neste processo. }\end{array}$ \\
\hline When? & Quando? & $\begin{array}{l}\text { Esta pergunta visa o estabelecimento de prazos para a } \\
\text { aplicação da ferramenta } 5 \mathrm{~W} 2 \mathrm{H} \text {, bem como da execução das } \\
\text { tarefas referentes a ela. }\end{array}$ \\
\hline Why? & Por quê? & $\begin{array}{l}\text { Esta pergunta visa justificar aplicação do } 5 \mathrm{~W} 2 \mathrm{H} \text {, destacando } \\
\text { a sua importância, quais as suas vantagens no setor, assim } \\
\text { como a oportunidade e a viabilidade de uma aplicação. }\end{array}$ \\
\hline How? & Como? & $\begin{array}{l}\text { Esta pergunta visa responder qual a metodologia que será } \\
\text { utilizada pelo setor para a aplicação, qual a forma mais prática } \\
\text { de executá-la, de acordo com o ramo de atividade e com a }\end{array}$ \\
\hline
\end{tabular}

Disponível em: https://www.nucleodoconhecimento.com.br/engenharia-de-producao/packing- 


\begin{tabular}{|l|l|l|}
\hline & $\begin{array}{l}\text { complexidade da empresa que está executando este } \\
\text { processo. }\end{array}$ \\
\hline $\begin{array}{l}\text { How } \\
\text { much? }\end{array}$ & Quanto & $\begin{array}{l}\text { Trata-se basicamente de um orçamento que indica quanto a } \\
\text { empresa pretende gastar na elaboração do } 5 \mathrm{~W} 2 \mathrm{H}\end{array}$ \\
\hline
\end{tabular}

Fonte: Dos autores (2015)

Esta justificativa tem como objetivo simplificar a compreensão da ferramenta $5 \mathrm{~W} 2 \mathrm{H}$, com vistas a facilitar o resultado obtido e, após aplicar, utiliza-lo como roteiro de aplicação desta ferramenta, que estarão elencados e detalhados no setor, bem como todos os procedimentos que devem ser adotados e apontar quais as melhorias que 0 setor deve realizar quanto a esta questão.

É fundamental ressaltar de que a legislação esta sempre em atualização e as mesmas devem ser acompanhadas para que o setor siga suas atividades de segurança do trabalho em sintonia com a rotina do setor, que tende constantemente a sofrer pequenas mudanças, assim como a ferramenta pode tornar-se obsoleta, o que pode trazer a necessidade de melhoria continua nos processos organizacionais, inclusive referentes à qualidade e, consequentemente, isso deverá impactar em mudanças periódicas no setor alimentício, visando qualidade total desses processos.

É preciso que o gestor vise verificar constantemente o setor, aplicando a ferramenta de modo a evitar possíveis problemas. Partindo da necessidade, a empresa deve estabelecer períodos para que esta atualização da ferramenta ocorra e é recomendado que se utilize novamente a ferramenta $5 \mathrm{~W} 2 \mathrm{H}$, visto que os envolvidos na criação do manual estarão acostumados com o mesmo padrão para sua atualização, como um método por sua praticidade e clareza.

Quadro 5: Perguntas da ferramenta 5W2H para a atualização $5 \mathrm{~W} 2 \mathrm{H}$ no setor alimentício.

Perguntas da ferramenta 5W2H para a atualização do setor alimentício
$5 \mathrm{~W}$
What?
O que?
O que é o setor alimentício?

RC: 52335

Disponível em: https://www.nucleodoconhecimento.com.br/engenharia-de-producao/packinghouse 


\begin{tabular}{|c|c|c|c|}
\hline & Who? & Quem? & $\begin{array}{l}\text { Quem irá atualizar o setor alimentício? Quais } \\
\text { serão os setores? Quem serão as pessoas } \\
\text { responsáveis? }\end{array}$ \\
\hline & Where? & Onde? & $\begin{array}{l}\text { Onde a ferramenta } 5 \mathrm{~W} 2 \mathrm{H} \text { será atualizada? Em } \\
\text { qual setor? }\end{array}$ \\
\hline & When? & Quando? & $\begin{array}{l}\text { Em que momento setor alimentício será } \\
\text { atualizado? Quais os prazos estabelecidos para o } \\
\text { cumprimento das tarefas? }\end{array}$ \\
\hline & Why? & Por quê? & $\begin{array}{l}\text { Por que atualizar a ferramenta } 5 \mathrm{~W} 2 \mathrm{H} \text { ? Qual a sua } \\
\text { importância? Qual o seu objetivo? Justificativa da } \\
\text { atualização da ferramenta } 5 \mathrm{~W} 2 \mathrm{H} \text { no setor } \\
\text { alimentício. }\end{array}$ \\
\hline $2 \mathrm{H}$ & How? & Como? & $\begin{array}{l}\text { Como o setor alimentício será atualizado? Qual a } \\
\text { sua metodologia? }\end{array}$ \\
\hline & $\begin{array}{l}\text { How } \\
\text { much? }\end{array}$ & $\begin{array}{l}\text { Quanto } \\
\text { custa? }\end{array}$ & $\begin{array}{l}\text { Quanto custa para a empresa atualizar esta } \\
\text { ferramenta já aplicada? Quais serão os gastos? }\end{array}$ \\
\hline
\end{tabular}

Fonte: Dos autores (2015)

Observa-se que no Quadro 5 que as sete perguntas referentes à ferramenta da Gestão da Qualidade 5W2H são conduzidas para o caso de uma atualização semelhante à direção estabelecida, mantendo a mesma essência, focando nos principais objetivos.

Como a criação já foi realizada, as perguntas referentes ao estudo de caso serão totalmente respondidas, pois se trata da mesma empresa, podendo haver alterações em alguns pontos. No Quadro 6 estão claras as propostas de cada pergunta relacionada à ferramenta da qualidade $5 \mathrm{~W} 2 \mathrm{H}$. 
Quadro 6: Propósito das perguntas referente as ferramentas da qualidade $5 \mathrm{~W} 2 \mathrm{H}$ para a aplicação no setor alimentício de uma empresa

Objetivos das perguntas da ferramenta $5 \mathrm{~W} 2 \mathrm{H}$ para a atualização do setor alimentício na empresa

\begin{tabular}{|c|c|c|}
\hline What? & O que? & $\begin{array}{l}\text { Esta pergunta visa apresentar o setor alimentício envolvidos } \\
\text { no processo, de modo a realizar uma apresentação básica do } \\
\text { mesmo e como ele funciona. A essência do setor de alimentos } \\
\text { o mantêm a mesma referente a criação do mesmo. }\end{array}$ \\
\hline Who? & Quem? & $\begin{array}{l}\text { A organização deverá estabelecer quais setores participarão } \\
\text { do processo de aplicação do } 5 \mathrm{~W} 2 \mathrm{H} \text { e quais serão as pessoas } \\
\text { responsáveis por ela, bem como o seu público alvo. Neste } \\
\text { dado momento o setor pode alterar os responsáveis pela } \\
\text { atualização, de modo a realizar uma maior interatividade dos } \\
\text { colaboradores com este processo, ou mesmo em casos da } \\
\text { entrada de novas pessoas na empresa. }\end{array}$ \\
\hline Where? & Onde? & $\begin{array}{l}\text { Esta pergunta visa basicamente responder em qual empresa } \\
\text { será aplicado o } 5 \mathrm{~W} 2 \mathrm{H} \text {, em caso de parcerias, quais setores } \\
\text { estão envolvidos neste processo. Por tratar-se da mesma } \\
\text { empresa, pode haver alteração em casos de parcerias. }\end{array}$ \\
\hline When? & Quando? & $\begin{array}{l}\text { Esta pergunta visa o estabelecimento de prazos para } \\
\text { aplicação do } 5 \mathrm{~W} 2 \mathrm{H} \text {, bem como da execução das tarefas } \\
\text { referentes a ela. }\end{array}$ \\
\hline Why? & Por quê? & $\begin{array}{l}\text { Esta pergunta visa justificar a aplicação da ferramenta, } \\
\text { destacando a sua importância, quais as suas vantagens no } \\
\text { setor, assim como a oportunidade e a viabilidade de sua } \\
\text { aplicação. }\end{array}$ \\
\hline How? & Como? & $\begin{array}{l}\text { Esta pergunta visa responder qual a metodologia que será } \\
\text { utilizada no setor para aplicar a ferramenta, qual a forma mais } \\
\text { prática de executá-la, de acordo com o ramo de atividade e } \\
\text { com a complexidade do setor o que está executando este }\end{array}$ \\
\hline
\end{tabular}




\begin{tabular}{|l|l|l|}
\hline & & $\begin{array}{l}\text { processo, bem como verificar a eficiência da metodologia } \\
\text { utilizada na aplicação da ferramenta. }\end{array}$ \\
\hline $\begin{array}{l}\text { How } \\
\text { much? }\end{array}$ & $\begin{array}{l}\text { Quanto } \\
\text { custa? }\end{array}$ & $\begin{array}{l}\text { Trata-se basicamente de um orçamento que indica quanto a } \\
\text { empresa pretende gastar na aplicação da ferramenta } 5 \mathrm{~W} 2 \mathrm{H}\end{array}$ \\
\hline
\end{tabular}

Fonte: Dos autores (2015)

O processo de aplicação da ferramenta $5 \mathrm{~W} 2 \mathrm{H}$ deverá ser utilizada repetidamente no setor desejável, sem desrespeitar o prazo estabelecido da implantação.

A aplicação da ferramenta segue a metodologia da gestão da qualidade $5 \mathrm{~W} 2 \mathrm{H}$, adequando as perguntas para qual setor obtiver, buscando a melhoria contínua nas suas metodologias da qualidade e, vale ressaltar que a implantação do $5 \mathrm{~W} 2 \mathrm{H}$ poderá ser colocada em prática em qualquer setor da empresa.

\section{RESULTADOS}

No Quadro 7 são indicados problemas que acarretavam tempo ocioso, desorganização, falta de higiene entre outras dificuldades diagnosticadas. Em seguida, na Tabela 8 são demonstrado o resumo dos resultados obtidos após a implantação.

Quadro 7: Demonstrativo de Resultados

Tabela Demonstrativa de Resultados

\begin{tabular}{|l|l|l|l|l|l|}
\hline Problemas & O que & Quanto isso & Solução & Benefício \\
a serem & & era & gerado & aplicada & gerado após \\
solucionad & & de & custo & & a \\
os & & para & a & & implantação \\
\hline
\end{tabular}

Disponível em: https://www.nucleodoconhecimento.com.br/engenharia-de-producao/packinghouse 


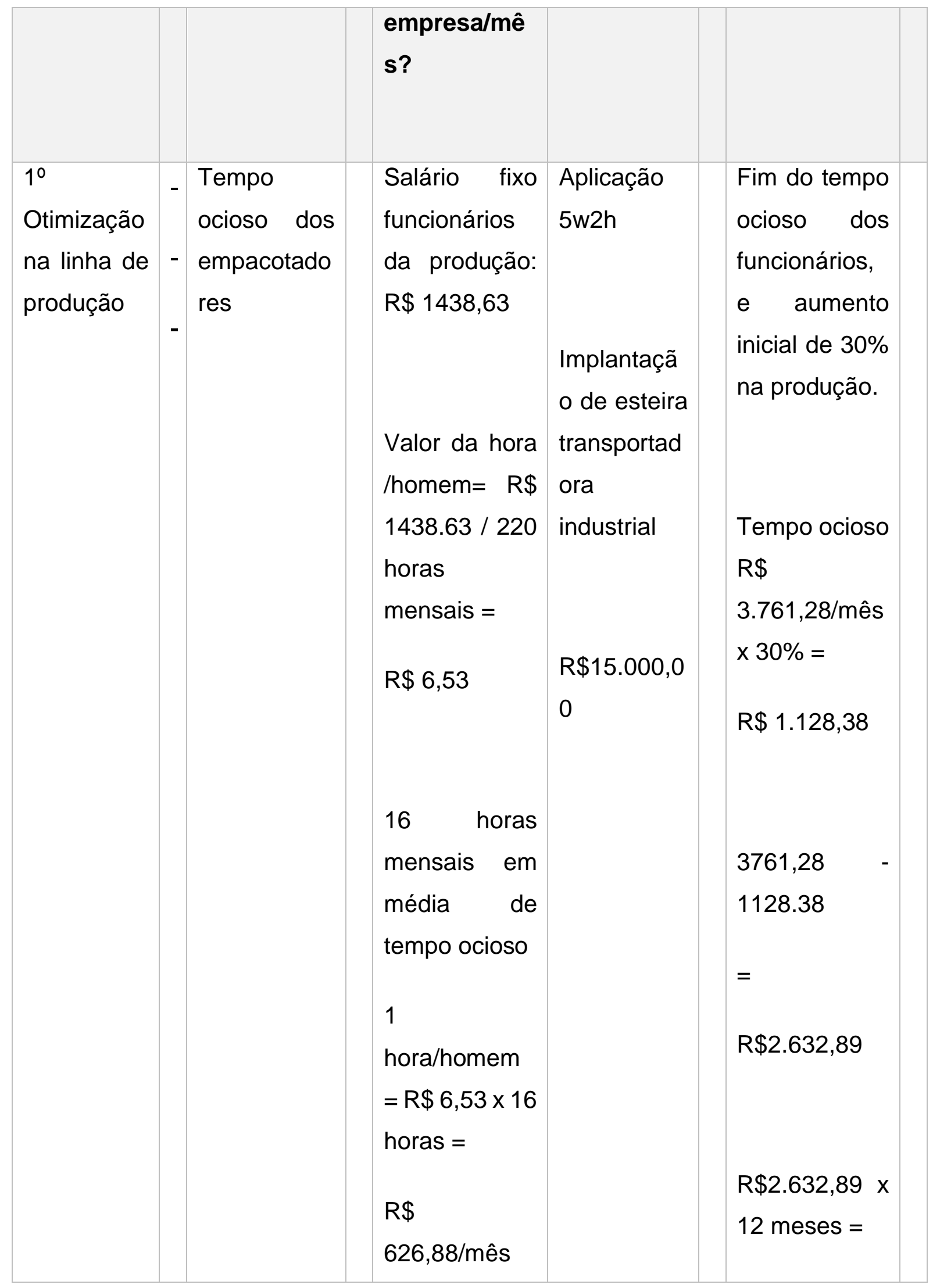




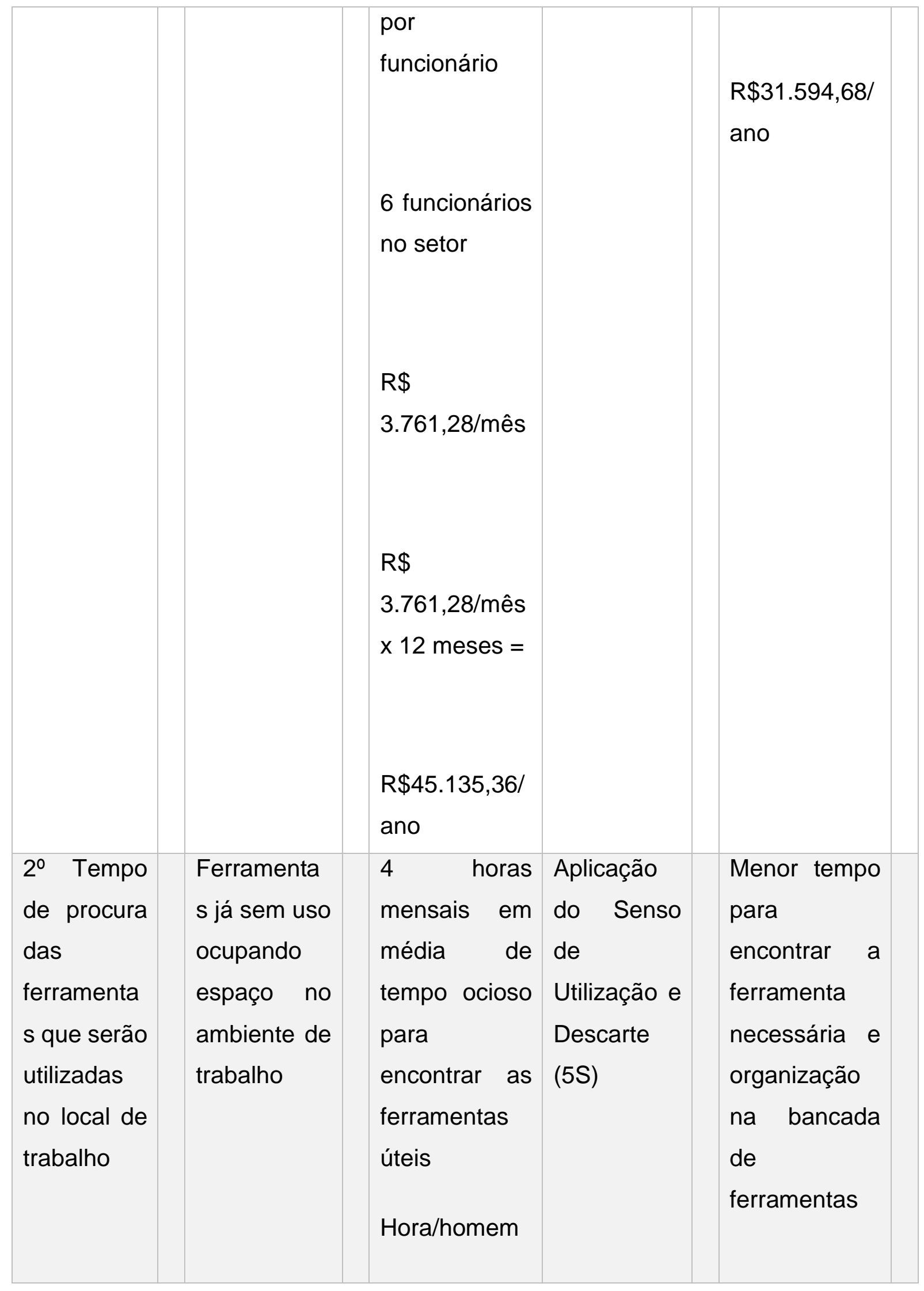

RC: 52335

Disponível em: https://www.nucleodoconhecimento.com.br/engenharia-de-producao/packinghouse 


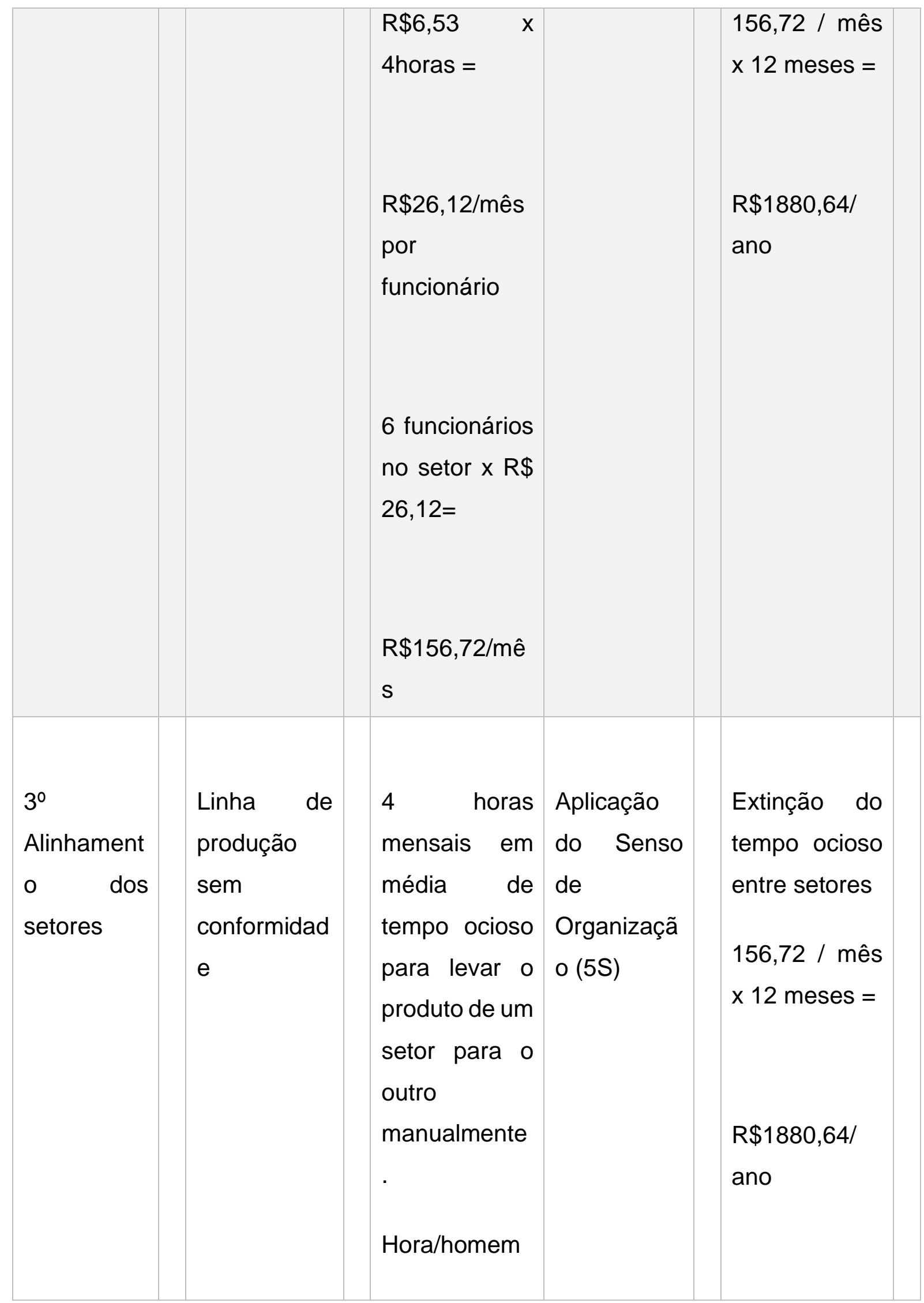

Disponível em: https://www.nucleodoconhecimento.com.br/engenharia-de-producao/packinghouse 


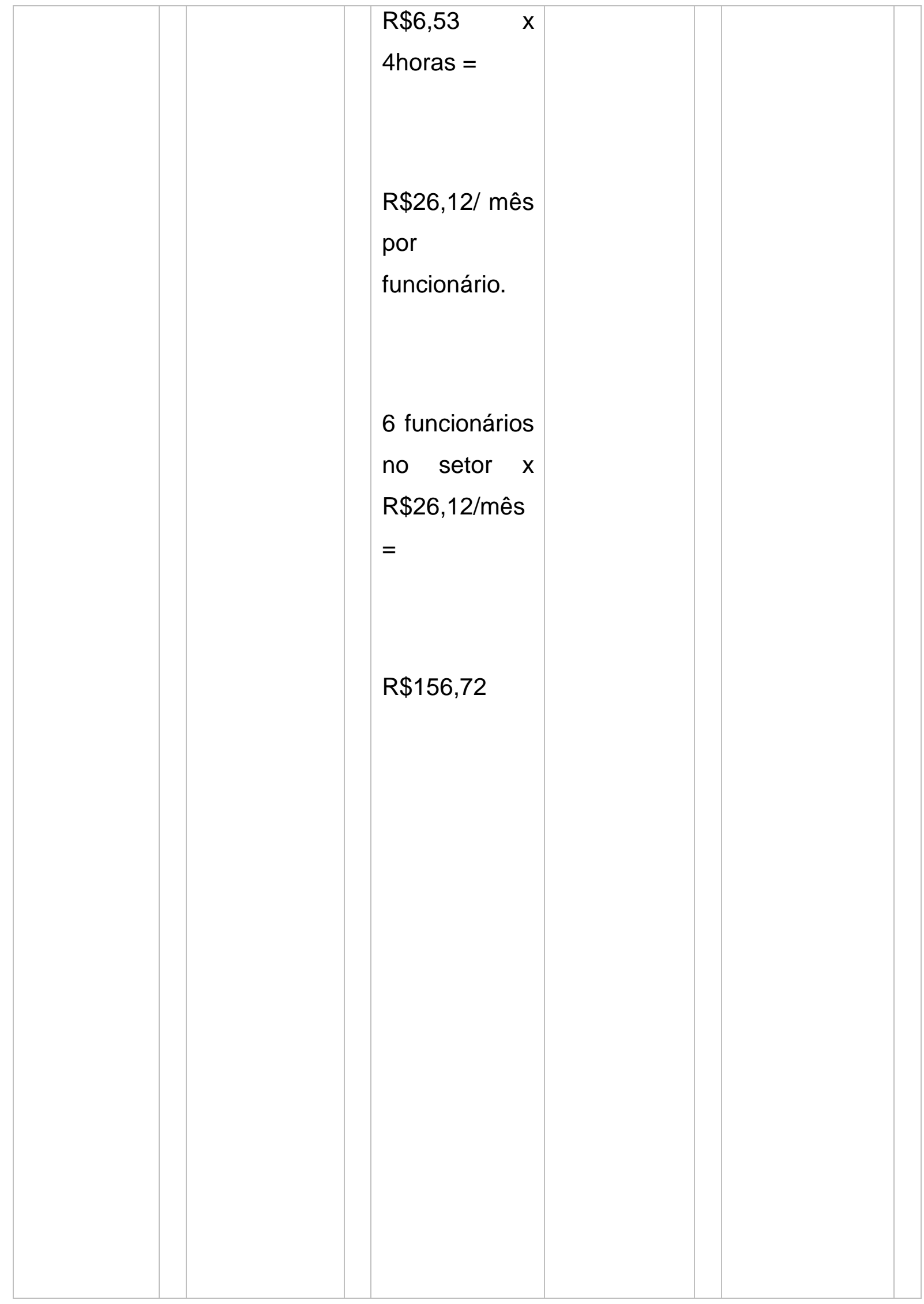

RC: 52335

Disponível em: https://www.nucleodoconhecimento.com.br/engenharia-de-producao/packinghouse 


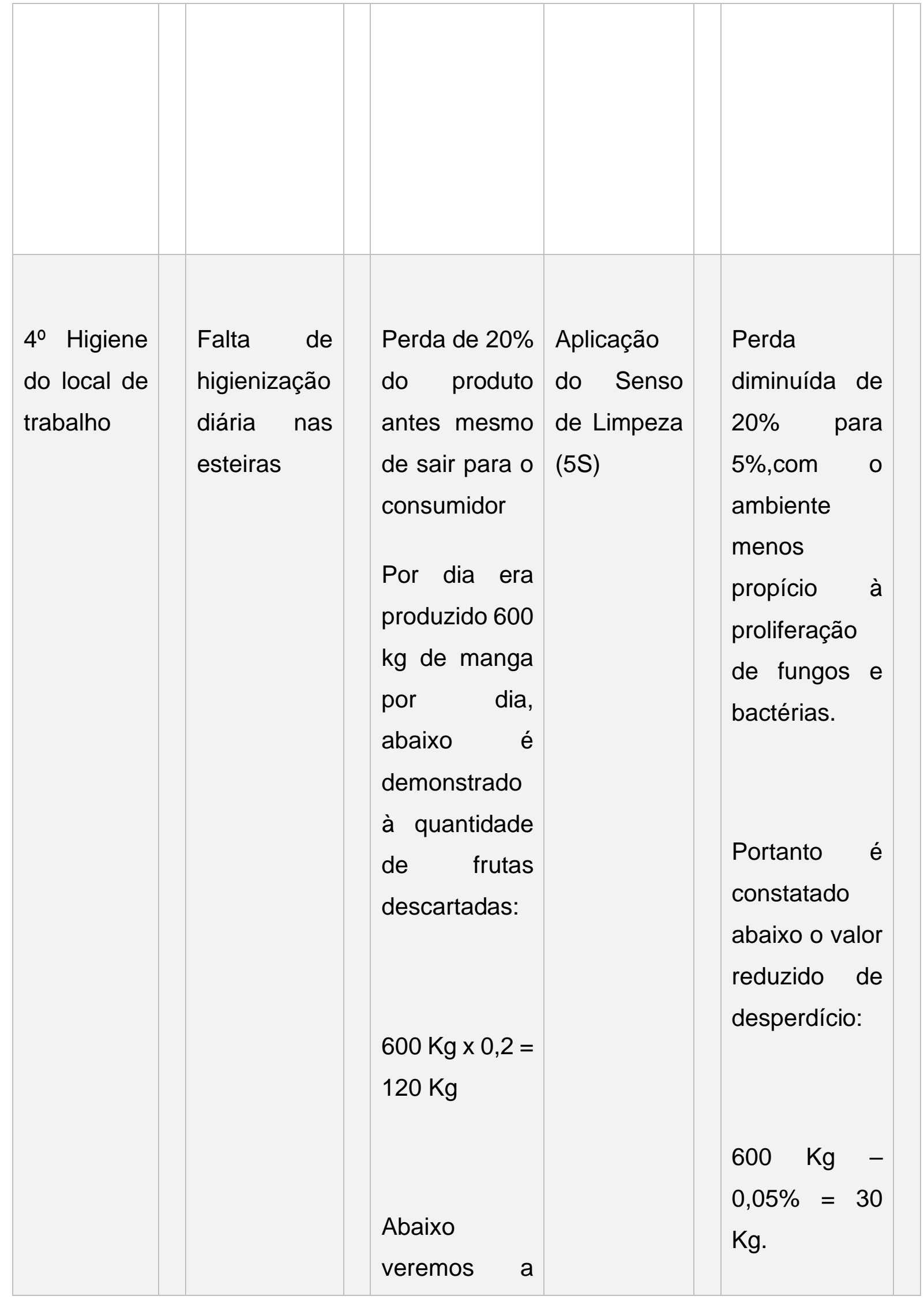

RC: 52335

Disponível em: https://www.nucleodoconhecimento.com.br/engenharia-de-producao/packinghouse 


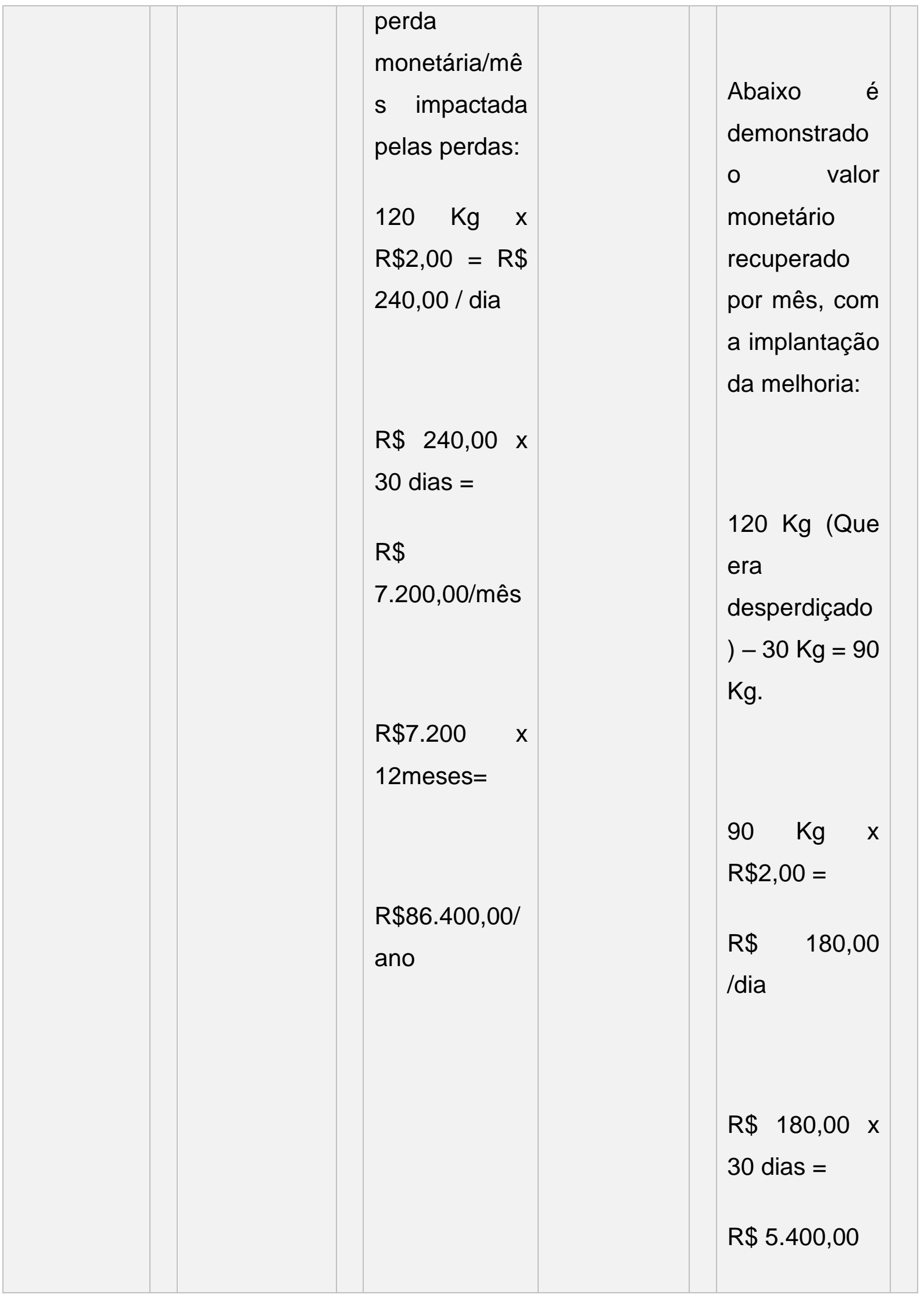

RC: 52335

Disponível em: https://www.nucleodoconhecimento.com.br/engenharia-de-producao/packinghouse 


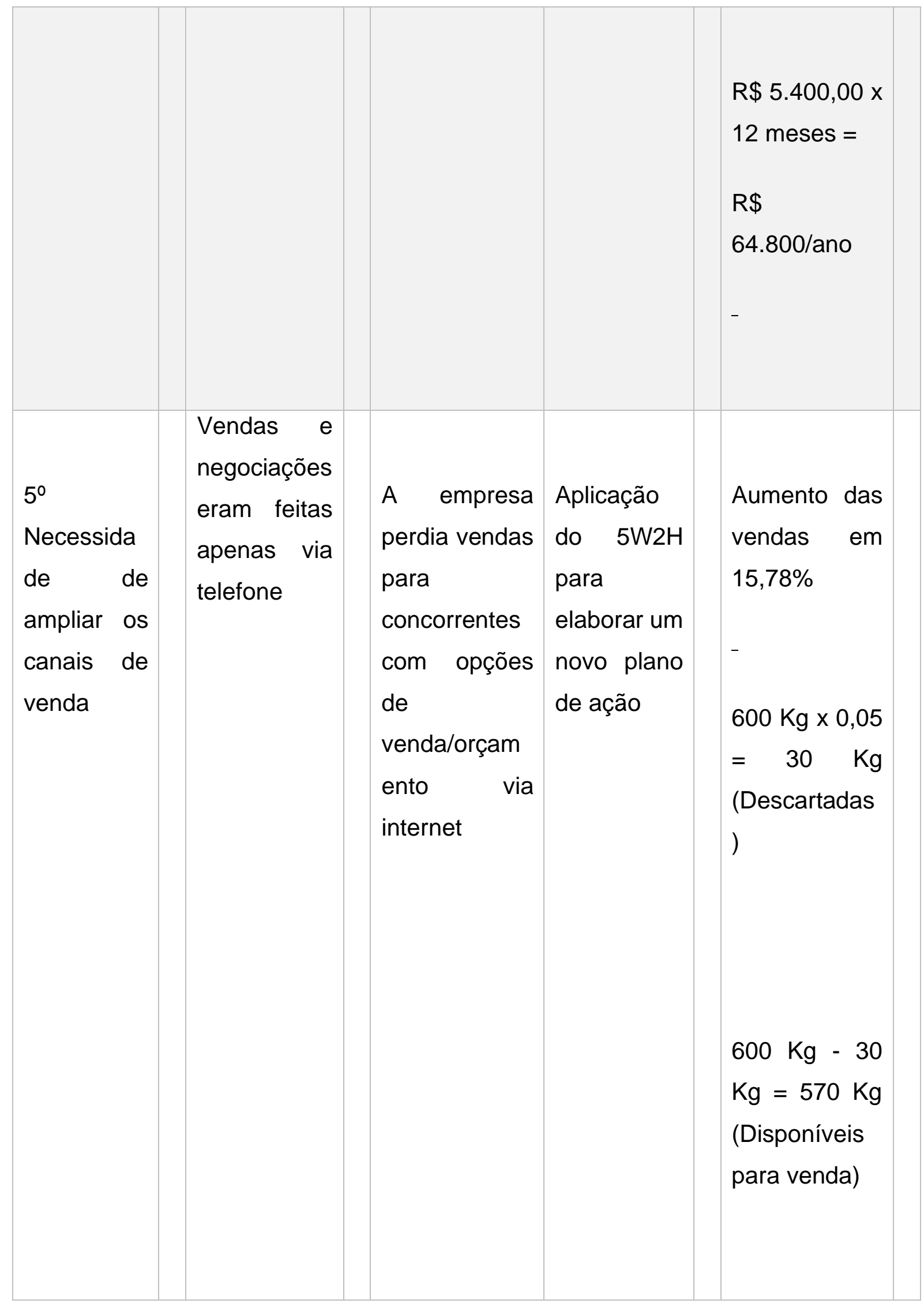

RC: 52335

Disponível em: https://www.nucleodoconhecimento.com.br/engenharia-de-producao/packinghouse 


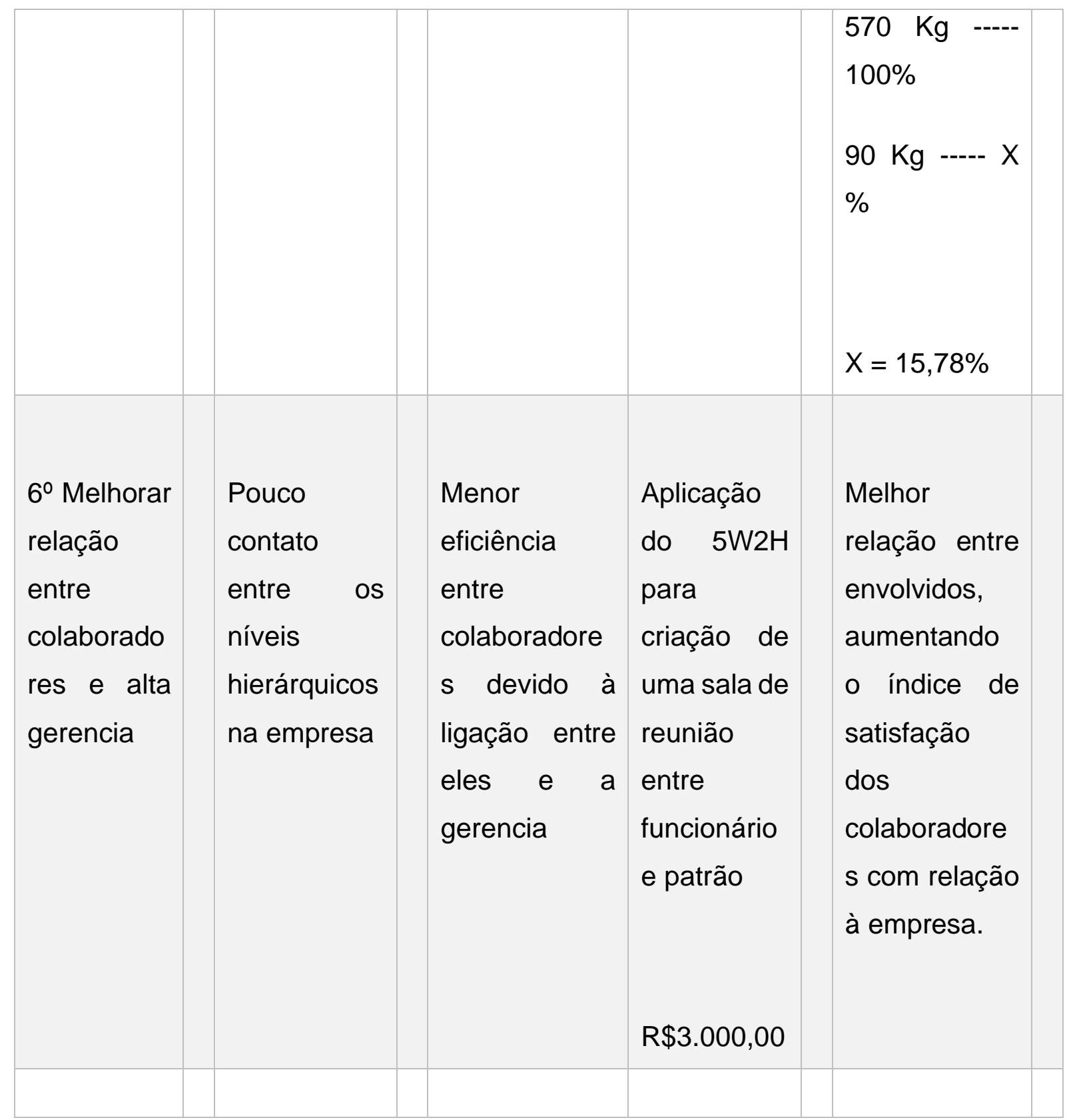

Fonte: Os autores (2020).

$\mathrm{Na}$ Tabela 8 demonstra os custos relacionados ao desperdício anual antes e após a implantação das ferramentas de gestão da qualidade 5 s e $5 \mathrm{~W} 2 \mathrm{H}$. 
Tabela 8: Cálculos financeiros

\begin{tabular}{|c|c|c|c|c|c|c|c|}
\hline \multicolumn{8}{|c|}{ Custos e disperdicios Anual } \\
\hline & Hom em/Hora & $\begin{array}{l}\text { Horas anual de } \\
\text { tempo ocioso }\end{array}$ & $\begin{array}{l}\text { Quantidade } \\
\text { de } \\
\text { funcionarios }\end{array}$ & $\begin{array}{r}\mathrm{Cu} \\
\text { por } \mathrm{f}\end{array}$ & $\begin{array}{l}\text { to Anual } \\
\text { ncionario }\end{array}$ & \multicolumn{2}{|c|}{ Custo total } \\
\hline Tempo ocioso dos empacotadores & 6,53 & 192 & 6 & RS & $1.253,76$ & $\mathrm{RS}$ & $7.522,56$ \\
\hline $\begin{array}{l}\text { Tempo de procura ferram entas que } \\
\text { serão usadas no local de trabalho }\end{array}$ & 6,53 & 48 & 6 & RS & 313,44 & $\mathrm{R} S$ & $1.880,64$ \\
\hline $\begin{array}{l}\text { Linha de produção sem } \\
\text { conformidade }\end{array}$ & 6,53 & 48 & 6 & $\mathrm{R} \$$ & 313,44 & $\mathrm{RS}$ & $1.880,64$ \\
\hline Custo Total Anual & & & & & & RS & $1.283,84$ \\
\hline
\end{tabular}

\begin{tabular}{|c|c|}
\hline \multicolumn{2}{|c|}{ Investimento } \\
\hline $\begin{array}{c}\text { Implantação de esteira } \\
\text { transportadora industrial }\end{array}$ & $\mathrm{R} \$ 15.000,00$ \\
\hline criação de uma sala de reunião & $\mathrm{R} \$ 3.000,00$ \\
\hline Total & $\mathrm{R} \$ 18.000,00$ \\
\hline
\end{tabular}

\begin{tabular}{|c|c|c|}
\hline \multicolumn{3}{|c|}{ Beneficio gerado após a implantação } \\
\hline & $\begin{array}{c}\text { Benefício gerado } \\
\text { após a implantação } \\
\text { mensal }\end{array}$ & $\begin{array}{c}\text { Benefício gerado } \\
\text { após a } \\
\text { implantação } \\
\text { Anual }\end{array}$ \\
\hline Tempo ocioso dos empacotadores & $\mathrm{R} \$ 2.632,89$ & $\mathrm{R} \$ 31.594,68$ \\
\hline Higiene no local de trabalho & $5.400,00$ & $\mathrm{R} \$ 64.800,00$ \\
\hline $\begin{array}{c}\text { Necessidade de ampliar os canais } \\
\text { de venda }\end{array}$ & $5.400,00$ & $\mathrm{R} \$ 64.800,00$ \\
\hline total & & $\boldsymbol{R} \$ \mathbf{1 6 1 . 1 9 4 , 6 8}$ \\
\hline
\end{tabular}

Fonte: Os autores (2020).

\section{CONSIDERAÇÕES FINAIS}

De acordo com o estudo quantitativo e conforme os demais capítulos do artigo cientifico, podemos destacar as seguintes conclusões:

1) As metodologias de $5 \mathrm{~s}$ e $5 \mathrm{~W} 2 \mathrm{H}$ tendem a agregar resultados exponenciais tornando-se fundamentais para diferenciar a empresa dos seus demais concorrentes.

2) Com análise dos benefícios adquiridos pela implantação adotada, foram verificados ganhos diretos e efetivos na qualidade do produto final, no manuseio, no armazenamento, havendo uma maior eficiência e produtividade da empresa, garantindo de modo integral a segurança alimentar; de modo a minimizar a imprecisão

RC: 52335

Disponível em: https://www.nucleodoconhecimento.com.br/engenharia-de-producao/packinghouse 
do processo evitando manipulação incorreta dos insumos e produtos alimentícios, proporcionando benefícios ao cliente e à saúde da empresa.

3) Investimentos por parte da empresa são medidas que podem garantir a segurança indispensável para que se diferencie no mercado, caso tais investimentos forem ignorados pode-se ocorrer o comprometimento da competitividade da empresa perante o mercado, tendendo a riscos com probabilidade de perda de capital.

Contudo, os estudos realizados ao longo desta pesquisa se coloca as seguintes recomendações para trabalhos futuros:

1) Realizar a aplicação das ferramentas da Gestão da Qualidade no setor de produção verificando os custos incorridos no processo produtivo e os custos de implantação das melhorias no prazo de um ano.

2) Efetuar a aplicação de outras ferramentas no setor de produção, tais como: Diagrama de Ishikawa, Diagrama de Pareto, Análise SWOT, Gráficos de Dispersão, Folha de Verificação; e comparar os resultados obtidos entre duas ferramentas.

3) Executar a aplicação das ferramentas no setor de Planejamento e Controle da Produção (PCP), como, Just in time, Sistema Kanban de Produção e Kaizen para obter maior resultado no setor de produção, e ter maior desempenho financeiro e produtivo na empresa.

\section{REFERÊNCIAS}

BOONE, Louis E.; KURTZ, David L. Marketing contemporâneo. Ed 8. Rio de Janeiro: LTC, 1998, 564p.

CANDELORO, Raúl. Não Tenha Dúvidas: Método 5W2H. Adimistradores.com. Disponível em <http:/www.administradores.com.br/artigos/negocios/nao-tenhaduvidas-metodo-5w2h/26583/>. 27/11/2008. Acessado em 18/04/2020. 
MALHOTRA, Naresh K. Pesquisa de marketing: uma orientação aplicada. 3.ed. Porto Alegre: Bookman, 2001.

NAKAGAWA, Marcelo. Ferramenta 5W2H - Plano de Ação para Empreendedores. Globo, 2014.

RIBEIRO, Haroldo. A certificação do 5S, PDCA Editora, 01 de Janeiro de 2013, 434p.

RIBEIRO, Haroldo. 5S: Um roteiro para uma implantação bem sucedida. Salvador, BA: Casa da qualidade, 1994. 99 p.

ROESCH, Sylvia Maria Azevedo. Projetos de Estágio e Pesquisa em Administração: guia para estágios, trabalhos de conclusão, dissertações e estudos de caso. 3. ed. São Paulo: Atlas, 2005.

SILVA, Alisson O. da, et al. Gestão da Qualidade: Aplicação da Ferramenta 5W2H como Plano de Ação para Projeto de Abertura de uma Empresa. Faculdade Horizontina - FAHOR, 2013.

SILVA, João Martins da. 5s - O Ambiente da Qualidade. 2ª ed. Belo Horizonte. Líttera Maciel, 1994.

VANTIN, Nadia. Ambiente de qualidade em uma biblioteca universitária: aplicação do $5 S$ e de um estilo participativo de administração. Ci. Inf., set./dez. 1999, p.333-339, vol. 28 , no. 3 .

VIEIRA, Valter Afonso. As tipologias, variações e características da pesquisa de marketing. Curitiba: Revista da FAE, 2002. p.61-70, v.5, n.1.

Enviado: Abril, 2020.

Aprovado: Junho, 2020. 